\title{
RECQL4 Gene Mutation
}

National Cancer Institute

\section{Source}

National Cancer Institute. RECQL4 Gene Mutation. NCI Thesaurus. Code C53977.

A change in the nucleotide sequence of the RECQL4 gene. 